believe, is incorrect. The fighting services have their own research departments. Possibly the fact that some of the industrial research work carried out at the National Physical Laboratory and the Chemical Research Laboratory, and by various research associations, may be applicable to naval or military purposes as well as to industrial purposes, has led to this misconception.

\section{The International Mind}

IN a recent article entitled "The International Mind" (Nature, Sept. 30) dealing with the work of the League of Nations in the field of international intellectual co-operation, it was suggested that the League should concentrate mainly on education and the Press, and that, in regard to the many other forms of co-operation in science, art, letters, politics, etc., it should content itself in the main with collect. ing data on the present position. A correspondent has pointed out that a compendium of information on this latter sphere of activity has in fact been issued by the League of Nations, in its "Handbook of International Organisations", and in its quarterly bulletins on the same subject, published by Messrs. Allen and Unwin, Ltd. The "Handbook" for 1929 is priced at $10 \mathrm{~s}$, and runs to 348 pages. Moreover, the League of Nations, as a complete list of its publications further indicates, has by no means overlooked the power of the Press, as a cultural or intellectual factor. A conference of "Press Experts" was held in 1927; also a European Conference on Transport of Newspapers; and its publicity methods are described in a pamphlet on "The League of Nations and the Press" published in connexion with the International Press Exhibition, Cologne, 1928.

\section{Statistical Methods in Technical Problems}

DURING recent years there have been considerable developments in the application of modern statistical methods to the technical problems of industry and agriculture. The Council of the Royal Statistical Society considers that the time is now opportune for the formal provision of facilities which will stimulate discussion of such problems. It has therefore been decided to form a special section of the Society for the purpose of promoting the application of methods of statistical analysis to industrial and agricultural problems. This new development of the Society's activities should certainly meet a real need, since in the research department of a large industrial firm or at an agricultural research institute, special investigations are frequently undertaken which involve careful planning and experiment before the most suitable statistical procedure is obtained, while in the ordinary course of day-to-day production and selling, there often arise problems of sampling and testing or questions as to whether measurements taken are used to the best advantage, and how far they are adequate for the purpose intended or even the extent to which some of them may be redundant. The facilities provided by the Section will be twofold : (1) the holding of regular meetings; and (2) the publication of a supplement to the Journal of the
Royal Statistical Society, devoted entirely to this aspect of statistical science. The first meeting will be held on Thursday, November 23, at the Hall of the Royal Society of Arts, John Street, Adelphi, London, W.C.2, at 5.30 p.m.

\section{"Research is the Door of To-morrow"}

THE motto quoted above is engraved over the porch of the new Post Office research station at Dollis Hill, which was opened by Mr. Ramsay MacDonald on October 23. The results of the work carried out in many of the laboratories fully justify this saying, so far as telephony and telegraphy are concerned. It was stated that the annual saving to the Post Office effected by 14 out of the 511 investigations carried out last year was $£ 190,000$. The station possesses very complete workshops so that all the apparatus required for research purposes can be at once constructed. The researches carried out are generally very thorough. For example, when testing automatic telephone apparatus, all the component parts, such as telephone dials, selector switches and relays are continuously operated to failure or destruction. This enables an accurate forecast to be made of the performance of new types of equipment under working conditions. In the physics laboratory, investigations are made of the properties of the various materials used in the construction of communication apparatus. The apparatus for the production of the high voltages necessary for testing new types of lightning arresters and safety valves is carefully screened off from the rest of the laboratory. A special laboratory is devoted to improving the speeding up of the trunk telephone service. It has led to the provision of new facilities for signalling over trunk telephone lines by means of voice frequency currents. The introduction of the teleprinter has greatly increased the work of the telegraph research laboratory. The results obtained by operating this instrument under various conditions are being carefully investigated.

THE metallurgical department of the Dollis Hill station is devoted to the examination of the microstructure of metals. It is used mainly for diagnosing the cause of failure in all types of engineering plant. The analysis of small amounts of metals either in the form of alloy or impurity is carried out by the spectrograph. The methods developed have had important applications in connexion with the analysis of the lead alloys used for making the sheaths of underground and submarine cables. The laboratory for testing telephone instruments can deal with them at the rate of a thousand a day and this speed enables every new and repaired instrument to be tested as it comes from the contractors. The apparatus developed as a primary standard of telephone efficiency gives a high quality transmission and reproduction of speech at definite and constant levels. Similar standards have been made by the larger telephone administrations of the world and form an international standard of reference. There are also acoustic and cable research laboratories which are carrying out useful work. In addition to 